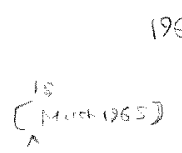

\title{
Discovery of the Worker Caste of Pheidole (P.) inquilina, New Combination (Hymenoptera: Formicidae) ${ }^{1}$
}

\author{
ARTHUR C. COLE \\ University of Tennessee, Knoxville
}

ABSTRACT

All castes of Pheidole inquilina (Wheeler) new combination, including the soldier which is reported for the first time, were found in nests of Pheidole pilifera coloradensis Emery, a host species, at the Nevada Test Site. The soldier is described and figured. The finding of the

soldier, with its obvious Pheidole characteristics, has made it necessary to transfer inquilina to the genus $P$ heidole Westwood and to synonymize the monobasic genus Epipheidole Wheeler.

Epipheidole inquilina Wheeler (1903, p. 664) was first described from a gynandromorph. ${ }^{2}$ Subsequent to its initial description, Wheeler $(1904$, p. 14) characterized the genus and fully described the sexes from specimens taken in nests of Pheidole pilifera coloradensis Emery near Colorado Springs, Colorado. Inasmuch as the nests contained only males and females

${ }^{1}$ The field work upon which this paper is based was accomplished under $U$, $S$. Atomic Energy Commission Contract no. AT (11-1) 786 (CETO project CEP 59.6), under the direction of the Department of Zoology and Entomology, Brigham
versity. Accepted for publication August 10, 1964.

versity. Accepted for publication Aumust 10, 1964 . making the gynandronorph the holotype, before be described the nther (normal) members of the type series. of inquilina and workers and soldiers only of coloradensis, Wheeler $(1904$, p. 2) concluded that inquilina must be a workerless species closely allied to Pheidole but deserving of new generic status.

Wheeler $(1904$, p. 16) was unable to find a coloradensis queen in any of the 3 nests he had discovered. One nest contained 3 males and numerous workers and soldiers of coloradensis, as well as 3 males of inquilina. Another colony contained a few workers and soldiers of coloradensis and 1 alate female of inquilina. In the third nest were coloradensis workers and soldiers together with a single queen, many dealate females, and a few males (as well as the gyn- 
andromorph mentioned above) of inquilina. Wheeler (1904, p. 17) speculated that, since tro queen of coloradensis had been found, inquilina "does not permit the females of its host species to mature."

Not until many years later did the status of inquilina change and even then not in nomenclature. Smith (1940, p. 104) announced the discovery of at single worker of this species which had been collected together with 4 associated inquilina queens from a nest of Pheidole pilifera (Roger) in Nebraska (probably at West Point by Lawrence Bruner) in 1883 . So, after 38 years, Wheeler's contention that inquilina is at workerless parasite was disproved. Although Smith (1940, p. 109) adnitted that the ant has many Phcidole characteristics and no really distinctive generic tratits of its own, he proposed no clange in nomenclature. His contention that Epipheidole is a valid genus was based on several points, namely 1) the apparent lack of a soldier caste, 2) the nearly complete loss of the worker caste, 3 ) the small size and peculiar habitus of the queen, 4) the distinctive structure of the worker, and 5) the inquilinous habit.

The recent discovery of the soldier caste now makes it necessary to transfer Epipheidole inquilina Wheeler to, and synonymize its generic name with, Pheidole. In the summer of 1962, during my studies of ants of the Nevada Test Site, I excavated, between June 22 and July 4,19 nests of $P$. pilifera coloradensis in an atomically disturbed pinyon-juniper community at an elevation of about 7000 feet. All colonies were in soil beneath rather large stones. E. inquilina was represented in each of 8 nests as follows: (1) 4 queens, 1 worker; (2) 1 queen; (3) 1 queen; (4) 15 s ; (5) 6 ․ 1 क; (6) 9 t; (7) 1 queen; (8) 1 worker, 1 soldier, 1 queen. All nests contained workers and soldiers of coloradensis and 1 nest (no. 2) had $6 z$ but no females of that species. A careful attempt was made to extract all occupants of a nest by transferring the excavated soil to a large ground cloth for examination. I was unable to find a coloradensis queen in any of the 8 nests. My attempts to maintain inquilina gitteens with coloradensis workers and soldiers in artificial nests were futile; the queens died within 3 days.

A description of the major (soldier) follows:

\section{Pheidole (P.) inquilina (Wheeler), new combination}

Epipheidole inquilina Wheeler, 1903, Bull. Amer. Mus. Nat. Hist. 19: 664, fig. 5, gynandromorph. Wheeler, 1904 ibid. $20: 15$; pl. 2 , figs. $12-17$; female, male. Smith, 1940. Proc. Entomol. Soc. Wash. 42: 106, fig. 1, worker. Smith, 1943, Amer. Midland Nat. 30; 299, fig. 7C, male. Smith, 1947, tbid. 37: 558, pl, 7, fig. 27, worker. Creighton, 1950, Bu1l. Mus. Comp. Zool. 104: 192, pl. 22. figs. 1-3, female, male. Smith, 1051, USDA Agr. Monogr. no. 2, p. 806 . Gregg, 1963, Ants of Colorado, p. 427 .

Major - $\mathrm{HL} 1.16 \mathrm{~mm}, \mathrm{HW} 1.26 \mathrm{~mm}, \mathrm{CI} 108.6, \mathrm{SL}$ $0.68 \mathrm{~mm}$, SI 53.9, WL $1.02 \mathrm{~mm}$, PL $0.27 \mathrm{~mm}^{3}$ PW $0.20 \mathrm{~mm}$, PPL, $0.22 \mathrm{~mm}$, PPW $0.39 \mathrm{~mm}$.

Head wider than long, the posterior corners very

sincluding the pedtincle and the collar.

4 Including the cottar. broadly and evenly convex, the occiptal border faintly and broadly excized medially. Longitudinal cephalic rugae rather weak, broken, very unevenly spaced, diverging into and fading out at the occipital corners; interrugal spaces shining, very finely granulose. Occiput smooth, without transverse rugae or striae.

Conformation of thorax, petiole, and postpetiole, in profle, as shown in Fig. 1; mesoepinotal impression shallow, sharply obtuse; posterior declivity of mesonotum meeting base of epinotum at approximately a $90^{\circ}$ angle; epinotal spines prominent, very broad basally, sharp apically, directed rather strongly backward: declivious face of epinotum nearly straight, meeting the base of the spine at a narrowly rounded angle; anterior declivity of petiolar node meeting the peduncle at a very weak, broadly rounded angle; apex of petiolar node subacute. In dorsal view, pronotal humeri strongly developed; apex of petiolar node deeply and broadly excised, the corners truncate; lateral connules of postpetiole prominent but rather short, subacute. Pronotum and mesonotum smooth, shining, very finely granulose; entire epinoturn densely and finely punctate, nearly opaque, the interspinal area with sparse, transverse striae. Petiole and postpetiole very densely and finely granulose, moderately shining. Gaster, even at cxtreme base, smooth and very shining. Head, epinotum, petiole, postpetiole, and gaster rather light brown; pronotum and mesonotum notably paler.

Discussion.-In general habitus, the soldier of $i n_{-}$ quilina resembles that of coloradensis (Fig. 2), but there are the following noteworthy differences: (1) much smaller size (average measurements of coloradensis: HL $1.63 \mathrm{~mm}$, HW $1.53 \mathrm{~mm}$, CI 93.9. SL 0.95 nm, SI 62.1, WL $1.79 \mathrm{~mm}$, PL $0.46 \mathrm{~mm}$, PW 0.34 mm, PPL $0.37 \mathrm{~mm}$, PPW $0.66 \mathrm{~mm}$ ), (2) head broader than long, (3) occipital corners more broadly rounded and occipital border not deeply excised, (4) occiput smooth and shining, without transverse rugae or striae, (5) dorsal contour of thorax, in profile, more irregular, (6) posterior declivity of mesonotum less steep, (7) meso-epinotal impression less pronounced, (8) epinotal declivity less steep and nearly straight, (9) epinotal spines more acute and directed more strongly backward, (10) thorax much
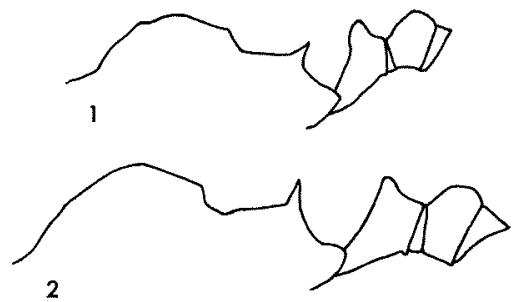

F1G. 1.- Pheidole inquilina soldier; contours of thorax, petiole, and postpetiole in profile.

FIG. 2.-Pheidole pilifera coloradensis soldier; contours of thorax, petiole, and postpetiole in profile. 
smoother and more shining, without rugae, (11) conformation of petiole and postpetiole, in profile, distinctive, and (12) color paler. The sharp epinotal spines of the inquilina soldier come as a surprise, for they are considerably more like those of the colora densis soldier than like the blunt and rather robust spines of the worker and sexes of inquilina.

My 2 workers of inquilina agree remarkably well with Smith's $(1940, \mathrm{p}, 106)$ lucid description and illustration. There are, however, 2 notable differences. I can find no trace of a frontal groove on the head of my specimens, and the posterior border of the head is not at all deeply emarginated. In profle view, the contour of the thoracic dorsum is strongly interrupted by especially the mesonotum, the anterior part of which is prominently elevated from the adjoining portion of the pronotum and is separated from it by a very strong promesonotal suture.

In conclusion, I quite agree with others that workers of inquitina are apparently rarely produced and that the queen of the host species is probably replaced by 1 or more inquilina queens. With such a small stimple size it is impossible even to estimate with what comparative frequency the soldier and worker are produced Creighton's (1950, p. 193) prediction that the soldier caste would eventually be found has been fulfilled. Inasmuch as the known range of inquilina has been extended westward from Nebraska and eastern Colorado to southern Nevada, there is every reason to suppose that additional colonies are in the vast intervening region and perhaps are even in nests of other members of the Pheidole pilifera complex.

\section{REFFRENCES CITED}

Creighton, w. S. 1950. The ants of North America. Bull. Mus. Comp. Zool. 104: 1-585.

Smith, M. R. 1940. The discovery of the worker caste of an inquiline ant, Epipheidole inquilina Wheeler. Proc. Entomol. Soc. Washington 42: 104-9.

Wheeler, W. M. 1903. Some new gyzandromorplous ants, with a review of the previotsly recorded cases. Bull. Amer. Mus. Nat. Hist. 19: 653 83 .

1904. Three new genera of inquiline arts from Colorado. Bull. Amer, Mus. Nat. Hist. 20:1-17. 